Collembola, one spider, four yellowish cut-worm like larvæ, one Stenus and several specimens of an Aleocharinid beetle. The appearance of insects on the under side of sticks and stones does not normally occur much before April.

\title{
THE PROTOCOLEOPTERA.
}

\author{
By Wm. T. M. Forbes, \\ Cornell University, Ithaca, New York.
}

Tillyard (Proc. Linn. Soc. N. S. W. vol. 49 p. 429, 1924) proposed an order with this name, based on a fore wing from the Permian of Australia. The present note intends to show that the form there described has no distinctive characters of the Coleoptera, but is more probably to be credited to the Orthoptera, with the possibility that it may be nearer to the ancestor of the Hemiptera.

The fossil (fig. 1) is a fore wing of characteristic Coleopterous form, except in one extremely important point, the presence of a deep notch at the articulation, and a basally extended anal lobe. This is a common feature of the Orthoptera, being more or less obvious in all the families, even in the cockroaches; and is correlated with a depression or fold at the base of the wing, which tends to bury the roots of veins $\mathrm{M}$ and $\mathrm{Cu}$ (Crampton '27). In the Coleoptera there is no such fold, but the articulation of the elytron is direct, and the veins (except Sc) all start out more or less on a level.

Secondly, the venation is rich in branches of main veins, with a few obliquely directed cross-veins. This is a common Orthopterous condition, though as a rule the supply of cross-veins is also rich. Fig. 2 shows the fore wing of a Gryllacridid, with the basal notch (in this form open and filled by a triangular group of sclerites), several precostal veins, Sc and $\mathrm{R}$ branched, the latter richly, $\mathrm{M}$ and $\mathrm{Cu}$ branched, their branches anastomosing, but entirely free from the veins above and below; an ambilent vein, which passes over the end of the anal fold $(\mathrm{Pl})$ without change of 
character, and several axillary (anal) veins, starting separately from the basal notch. This form does not show the oblique cross-veins, but they are obvious in many crickets, at least on the dorsal part of the wing. In the form figured (Eneoptera surinamensis) the venation is richer than in Protocoleus, but the

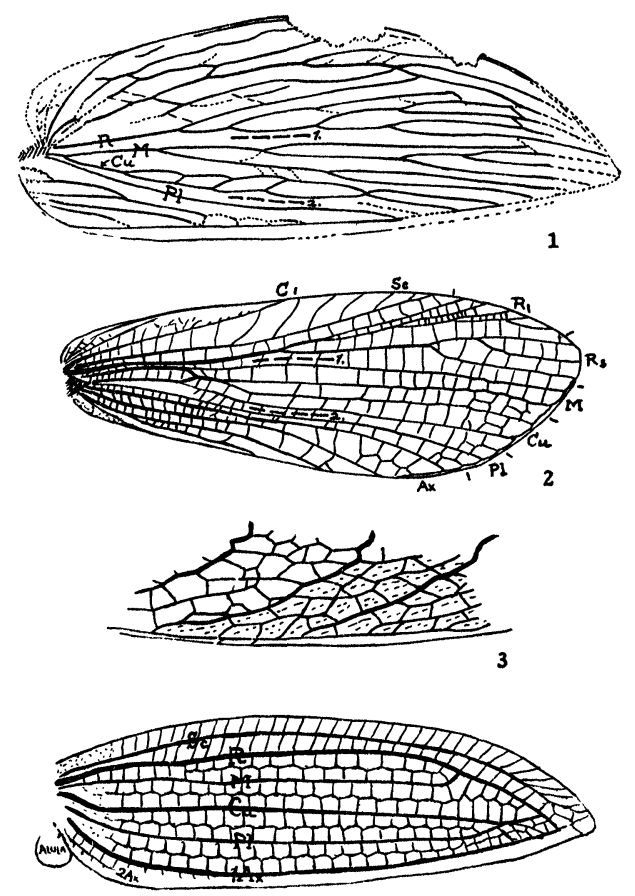

Fig. 1. 1, Protocoleus, mainly after Tillard's photograph, (Pl. 46), supplemented by his restoration (fig. 3, p. 432); 2, Gryllacris (Orthoptera, Gryllacrididæ); fore wing; 3, Eneoptera surinamensis (Orthoptera, Gryllidæ); portion of inner margin of fore wing; 4, Venation of Coleopterous elytron, synthesized mainly from venation of Cupes and tracheation of Tenebrio.

general character is plainly the same. In other forms (Gryllinæ etc.) the veins are even more regular than in Protocoleus. The other characters are common to the Gryllacrididæ and Protocoleus, though the whole is distorted to form a functional elytron and the breadth of the veinless margin is exaggerated. Even in the wing as preserved there is a well-veined precostal region, 
and the photograph seems to leave a possibility that some has been lost, as indicated by dotted lines in the figure; $\mathrm{M}$ and $\mathrm{Cu}$ are well bound by cross-veins, though not actually anastomosing, and the veinless paths separating them from $R$ and the anal system are striking,-- the most distinctive feature of the wing.

On the other hand the Coleoptera, as shown by the forms that have veins on the elytron (fig. 4) have unbranched veins, with regularly arranged cross-veins forming double rows of cells between them; and $\mathrm{M}$ and $\mathrm{Cu}$ noticeably avoid each other, each tending to fuse with its other neighbor in the outer part of the wing,- - a very distinctive wing.

In summary,-A: Resemblances of Protocoleus to Orthoptera and partly to Hemiptera:

1, Precostals present

2, Main veins richly branched

3 , Cross-veins few, and oblique

4, Anal lobe extended basally

5, $\mathrm{M}$ associated with $\mathrm{Cu}, \mathrm{R}$ and anals independent

6 , Plical vein (the one lying in the fold) running to inner margin, as in cockroaches and Hemiptera

B: Characters typical of the Coleoptera (but shared by Diploptera in the Orthoptera s. 1.)

1, Inner margin straight, the elytra no doubt meeting in the middle of the back than R.

2, Apex pointed (Tillyard in lit.) and located at $M$ rather

C: Characters of the Coleoptera not shared by Protocoleus:

1, Costa marginal (also some Orthoptera, but not universal)

2 , All veins simple (the prototype no doubt with terminal branching)

3, Cross-veins numerous, two-ranked and transverse

4 , Base of wing simple, the anal veins when traceable run directly into the articulation

$5, \mathrm{M}$ running into $\mathrm{R}, \mathrm{Cu}$ into the plical vein.

6 , Plical vein running to apex.

I then formally refer Protocoleus to the Orthoptera, where it will form a well characterized family related to the Gryllacrididæ, 
distinguished mainly by the elytriform fore wing with apex at Media.

Note: In view of the uncertainty prevailing as to the homology of the anal veins in the various orders of insects, I hereby propose the term Plical (Pl) to designate, without any implication of homology, a vein or veins closely associated with the anal fold, and more or less set off from the cubitus and from the other anals. For the latter (excluding the plical or plicals) the term Axillary, already in use in this sense in the Lepidoptera and Orthoptera, may be used, restricting that term, then, to anals associated with the anal fan rather than the fold. The maximum number of plical veins will be three (hind wing of Blattoidea and Mastotermes), one of them being in that case free, one supplied by a trachea coming off the anal fan, and the third sometimes with a free trachea, but more often supplied from the base of the cubital trachea. In higher forms there will be in general one Plical, but it is not clear to which of the three in the Blattoidea (if any) it corresponds. 

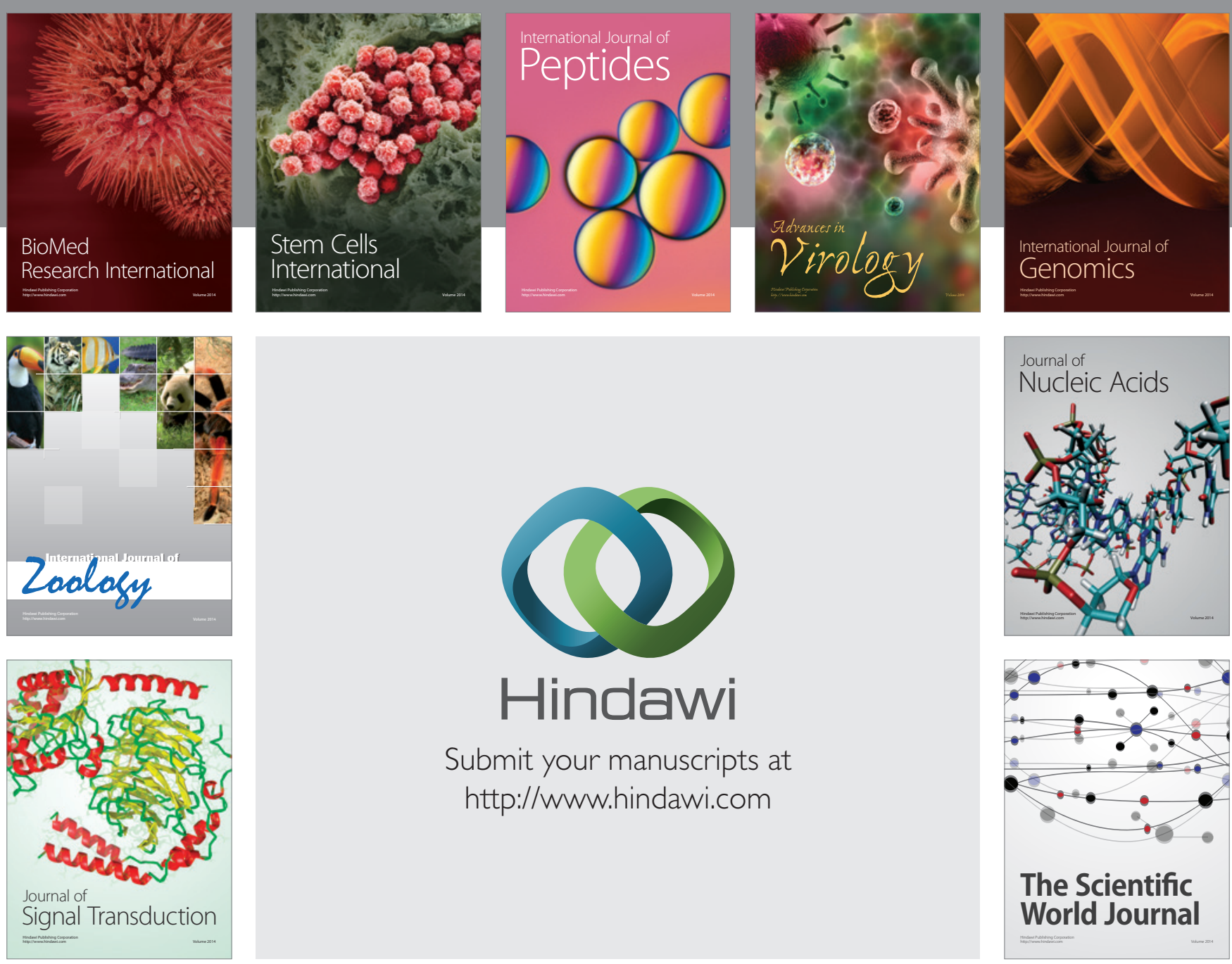

Submit your manuscripts at

http://www.hindawi.com
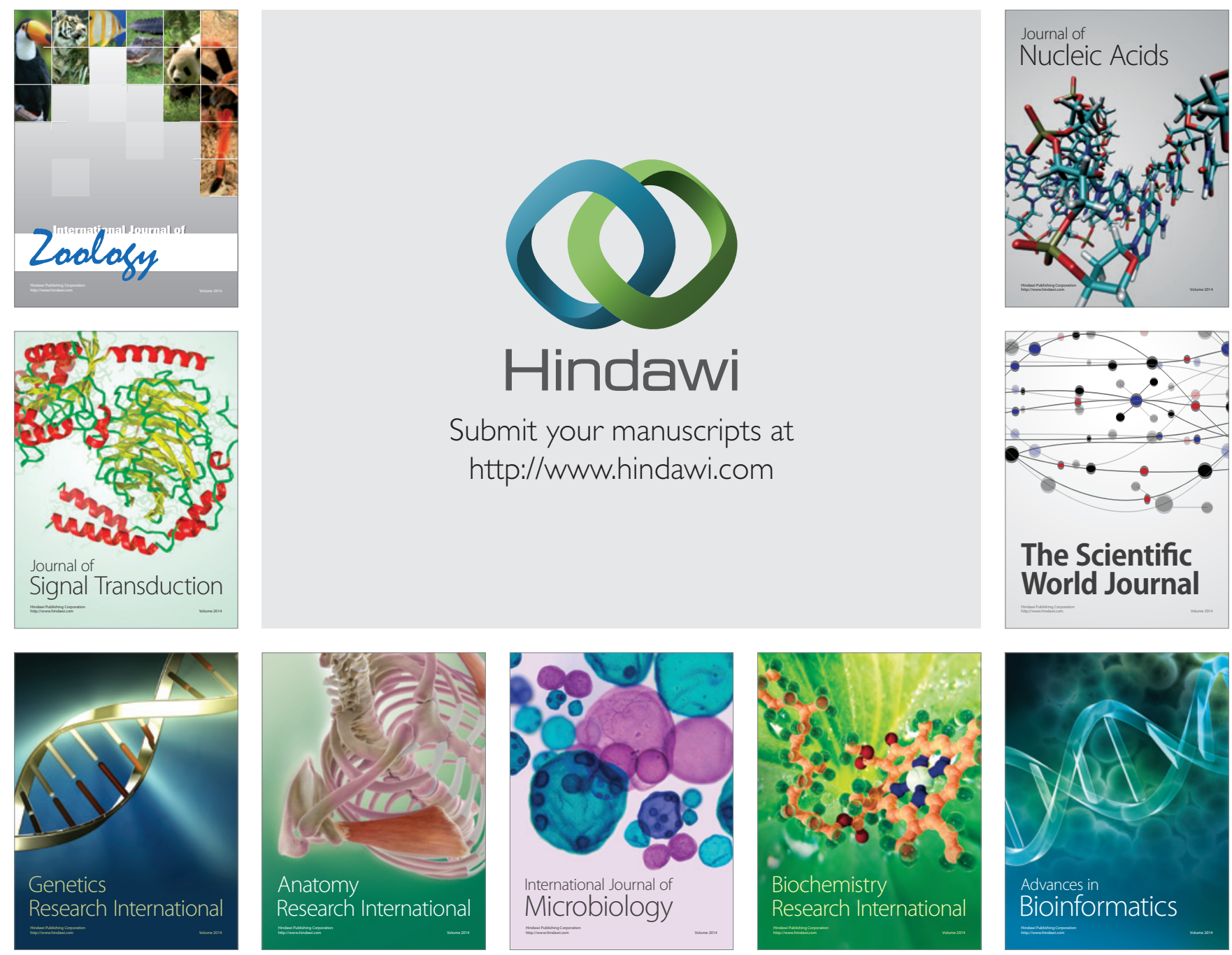

The Scientific World Journal
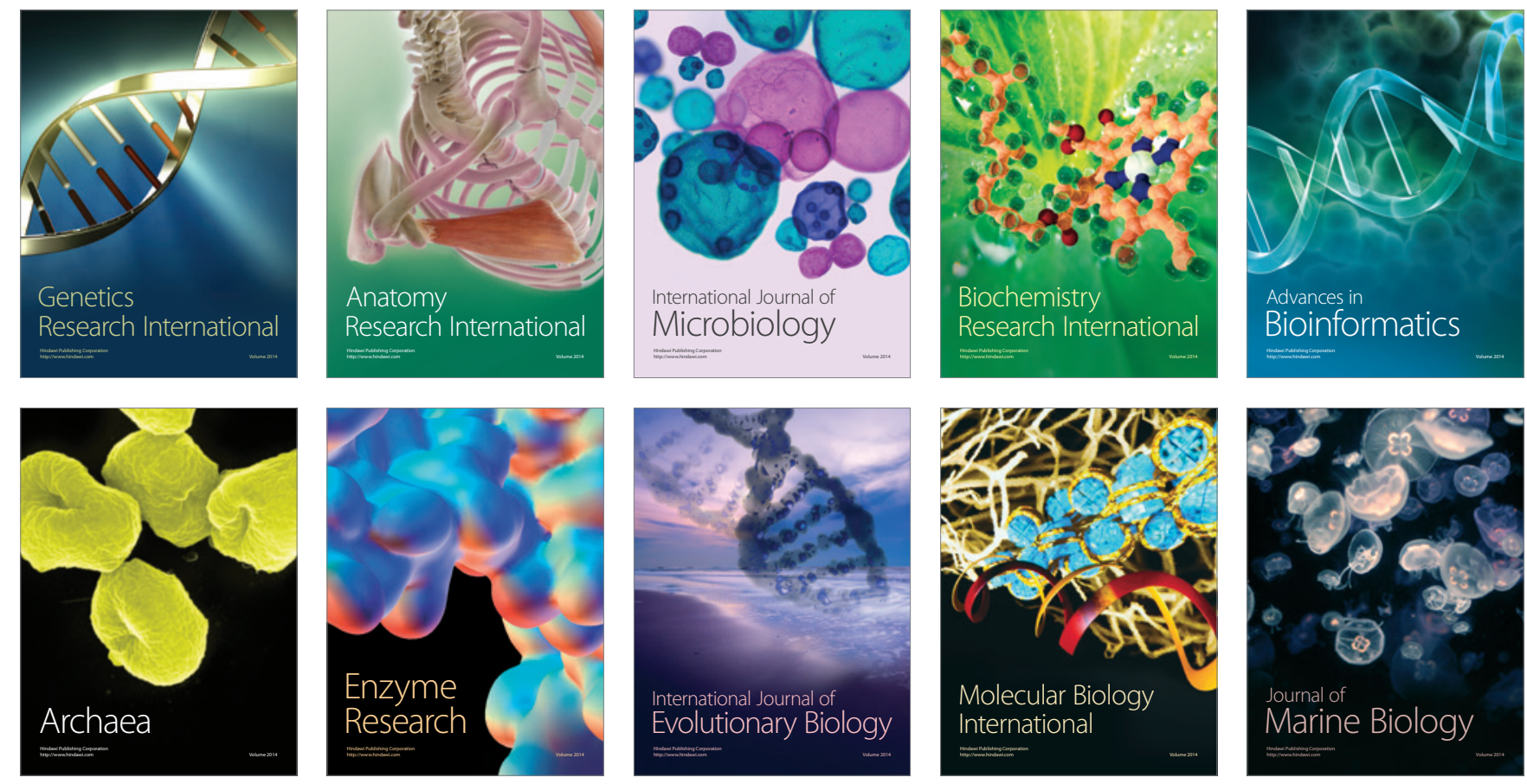